\title{
Determination of the most appropriate surgical treatment in syndesmotic injury of ankle joint: Application of Taguchi method
}

\author{
H. Göçer*, A. Çirakli**, L. Uğur***, A. Yildiz ${ }^{* * * *}$, S. Karadeniz****** \\ *Ondokuz Mayls University, School of Medicine, Department of Orthopaedics and Traumatology, Samsun ,Turkey, \\ E-mail: drhasangocer@hotmail.com \\ **Kayseri Education and Research Hospital, Department of Orthopaedics and Traumatology, Kayseri ,Turkey, \\ E-mail: alperomu@gmail.com \\ ***Amasya University, Faculty of Technology, Department of Automotive Engineering, Amasya, Turkey, \\ E-mail:leventozge@gmail.com \\ ****Amasya University, Faculty of Technology, Department of Automotive Engineering, Amasya, Turkey, \\ E-mail: aytac.yildiz@amasya.edu.tr \\ *****Amasya University, School of Medicine, Department of Orthopaedics and Traumatology, Amasya ,Turkey, \\ E-mail:drskaradeniz@hotmail.com
}

cross $^{\text {ref }}$ http://dx.doi.org/10.5755/j01.mech.23.1.14024

\section{Introduction}

The stability of the syndesmotic joint between the distal tibia and fibula is mostly maintained by the ligaments between these two joints, rather than the bony structures. This joint is held together by the anteroinferior tibiofibular ligament (AITFL), posterior inferior tibiofibular ligament (PITFL), and interosseous ligament (IOL). IOL is a pyramid-shaped ligament traveling from the proximal tibia to the distal fibula. In biomechanical studies performed by Ogilvie-Harris et al. (1994), nearly $36 \%$ of syndesmotic stability was attributed to the AITFL, and $41 \%$ and $23 \%$ of it to the PITFL and IOL, respectively [1]. Syndesmotic injury is observed in approximately $10 \%$ of ankle injuries [2]. If not repaired properly, syndesmotic injury may lead to instability of the ankle, chronic pain, and early osteoarthritic changes in the joint surfaces of the tibia, fibula, and talus [3,4]. Various clinical and biomechanical studies have been performed related to syndesmotic injury and its treatment methods [5-7]. As in all orthopedic operations, the most widely used method is screw fixation. However, complications such as postoperative screw breaking, syndesmotic separation, and instability have been reported in screw fixation $[6,8,9]$.

Studies generally involve the clinical and biomechanical aspects, or those performed on cadavers; however, results may vary when standards of costs, timing, and situations are not maintained. Therefore, digital methods that are more effective and that provide infinite reproducibility in standard conditions are becoming widespread.

The present biomechanical study determined the influences of screw diameter, screw number, number of cortices and angle of screw insertion on joint stability and stress exerted on the screw, by varying the abovementioned parameters, and by using finite element analysis and Taguchi method. We thus aimed to determine the fixation method that produces the best stability and the least stress.

\section{Materials and methods}

\subsection{Preparation of the three-dimensional model}

CT images of a $75 \mathrm{~kg}$, 35-year-old healthy subject were taken to produce three-dimensional models. Lower extremity CT scanning (Toshiba Aquilion CT device) was performed at the Akdeniz University Hospital. Rough data was scanned in DICOM (Digital Imaging and Communications in Medicine) format, and with $120 \mathrm{Kv}, 0.75-\mathrm{mm}$ pixel size, and $512 \times 512$ pixel resolution; a total of 1000 sections were obtained. In order to produce three-dimensional models of the lower extremity components, these sections were processed in the MIMICS ${ }^{\circledR} 12.11$ (Materialise's Interactive Medical Image Control System/ Materialise NV, Belgium) program.

In order to eliminate shining (artifact), and to achieve geometric correction and thus to obtain the accurate geometry in the three-dimensional models of bone structures (tibia, fibula, talus, and calcaneus) of the lower extremity, geometries were converted from MIMICS software to STL (stereolithography) format, and were then processed in the GEOMAGIC® Studio program, which is a $3 \mathrm{D}$ reverse engineering software.

In this reverse engineering software, procedures such as smoothing surface roughness, filling cavities, elimination of peakedness, and revision of surface coincidences were performed, and NURBS (Non-Uniform Rational BSplines) surfaces were obtained. Bone models produced by these corrections were processed by Solid Works ${ }^{\circledR}$ (Dassault Systems, USA) software, and cancellous bone structures were modeled. The 3D model of the lower extremity was thus produced as shown in Fig. 1.

In this study, cortical screws frequently used in syndesmotic injuries (with diameters of $3.5 \mathrm{~mm}$ and $4.5 \mathrm{~mm}$, in lengths of $45 \mathrm{~mm}$ and $65 \mathrm{~mm}$ ) were designed three-dimensionally using the Solidworks program. Cortical screws were placed singly (each $3.5 \mathrm{~mm}$ and $4.5 \mathrm{~mm}$ in diameter), and also in double, parallel to the joint level and $25 \mathrm{~mm}$ high to this level. The distance between the screws was $10 \mathrm{~mm}$, and placement was achieved from the fibula to tibia at a 30 degree anterior angle, and through three and four cortices (Fig. 1, a-d). In addition, by applying a new screwing method; screws were each placed singly, and also in double into the distal end of fibula at an angle of 30 degrees to the joint level, from the fibula to tibia, through three and four cortices; the distance between them 
was $10 \mathrm{~cm}$ (Fig. 1, e-h). Sixteen different models were thus produced.

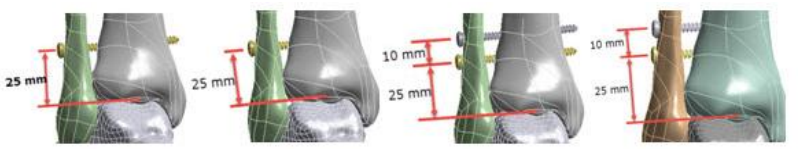

a

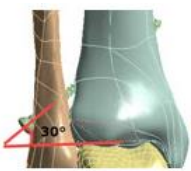

b

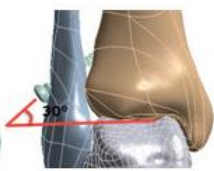

f

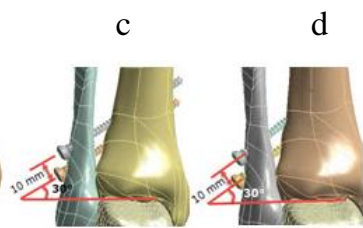

g shown in Fig. 2, c, the following descriptions were made at the standing position: the distal portion of calcaneus on fix support, no separation between bone structures, and frictionless contact between the cortical screw and bone structures. The pressure force applied to the tibia was as follows: $40 \%$ and $1031 \mathrm{~N}$ to the medial of upper surface, and $60 \%$ and $1547 \mathrm{~N}$ to the lateral surface (Fig. 2, b) [13-16].

\subsection{Modelling with the taguchi method}

Classical experimental design methods are not effective because of industrial conditions. The increase in the number of factors affecting the system leads to a rapid increase in the number of experiments required, increase in costs, and difficulties in application. In such cases, the Taguchi method is more effective and easier to apply [17]. The Taguchi method is a well-known technique that provides systematic and effective methodology for process optimization. It is used worldwide for product design and process optimization [18]. It is also widely used in engineering analyses because it decreases the number of experiments, and also production and test costs [19]. Preexperimental studies thus lead to a profound decrease in the number of experiments required. The main purpose of the Taguchi method is to reduce variability that may influence the target value. It is based on experimental design. This method adds the robust design and orthogonal lines concepts to the fractional factorial design of experiments [17]. In this method of experimental design, results are evaluated by converting them to the signal-to-noise ratio $(\mathrm{S} / \mathrm{N})$. The $\mathrm{S} / \mathrm{N}$ value is calculated and analyzed in different ways depending on the goal of the experiment and target value, and for static designs, signal-to-noise ratio values are as follows: smaller is better, larger is better, nominal is best $[17,20]$. Another important factor is the balance in experimental design; in other words, it must provide an evaluation of the factors independently, and to achieve this aim, equal numbers of samplings must be applied for different levels of each factor, and tested under every condition tested [17]. The main steps of the Taguchi method are as follows: determination of the factors and interactions, determination of the levels of each factor, selection of the convenient orthogonal matrix, transfer of the factors and interactions to the columns of orthogonal matrix, application of the experiments, and analysis of data and determination of the best convenient levels [21].

In the present study, 16 different models described above, and data obtained from these models were used, and the Taguchi method was applied for modelling design and analysis. We aimed to determine the most appropriate model and the best of the selected model parameters, by considering the minimum equivalent von Mises stress value. We analyzed 16 different models produced by considering straight or oblique insertions of the screws. To observe the differences between these types of insertions, 16 different models were analyzed in three groups: group 1 included eight models that received straight screw placement; group 2 included eight models that received oblique screw placement; group 3 included 16 models that received both straight and oblique screw placements. Data were evaluated by the Taguchi method, and three different modelling designs were produced. Analyses of these modelling designs are mentioned below.

In addition, as reported in various studies and as 
2.4. Modelling designs produced by considering straight (group 1) and oblique (group 2) placements of the screws

Parameters and levels determined in two different analyses are shown in Table 2 .

Model parameters and levels

\begin{tabular}{|l|c|c|c|c|c|c|c|}
\hline \multicolumn{3}{|c|}{ GROUP 1 } & \multicolumn{4}{c|}{ GROUP 2 } \\
\hline $\begin{array}{c}\text { Sym } \\
\text { bol }\end{array}$ & $\begin{array}{c}\text { Parame- } \\
\text { ters }\end{array}$ & Level 1 & Level 2 & $\begin{array}{l}\text { Sym } \\
\text { bol }\end{array}$ & $\begin{array}{l}\text { Parame- } \\
\text { ters }\end{array}$ & Level 1 & Level 2 \\
\hline A & $\begin{array}{l}\text { Number } \\
\text { of Corti- } \\
\text { ces }\end{array}$ & 3 & 4 & A & $\begin{array}{l}\text { Number of } \\
\text { Cortices }\end{array}$ & 3 & 4 \\
\hline B & $\begin{array}{l}\text { Number } \\
\text { of Screws }\end{array}$ & 1 & 2 & B & $\begin{array}{l}\text { Number of } \\
\text { Screws }\end{array}$ & 1 & 2 \\
\hline C & $\begin{array}{l}\text { Screw } \\
\text { Diameter, } \\
\text { mm }\end{array}$ & 3.5 & 4.5 & C & $\begin{array}{l}\text { Screw } \\
\text { Diameter, } \\
\text { mm }\end{array}$ & 3.5 & 4.5 \\
\hline
\end{tabular}

When the model parameters in Table 2 were considered, Taguchi L8 orthogonal array including eight models was determined to be the most appropriate design. Because this study aimed to determine the minimum equivalent von Mises stress value, the "smallest is best" analysis was used. L8 modelling design determined by the aid of 'minitab 17' software, equivalent von Mises stress ( $\mathrm{MPa})$ results obtained from modelling studies, and signal-tonoise ratio $(\mathrm{S} / \mathrm{N})$ values are given in Table 3 . The $\mathrm{S} / \mathrm{N}$ ratio analysis of each control parameter for the equivalent von Mises stress is shown in Table 4.

Table 3

Modelling designs produced by using L8 orthogonal array, modelling results and $\mathrm{S} / \mathrm{N}$ ratio

\begin{tabular}{|c|c|c|c|c|c|c|c|}
\cline { 2 - 8 } \multicolumn{1}{c|}{} & $\begin{array}{l}\text { Parame- } \\
\text { ters }\end{array}$ & \multicolumn{2}{c|}{ GROUP 1 } & \multicolumn{2}{c|}{ GROUP 2 } \\
\hline $\begin{array}{c}\text { Model } \\
\text { No }\end{array}$ & $\mathbf{A}$ & $\mathbf{B}$ & $\mathbf{C}$ & $\begin{array}{l}\text { Equivalent } \\
\text { von Mises } \\
\text { Stress } \\
\text { MPa) }\end{array}$ & $\begin{array}{l}\text { Equiva- } \\
\text { lent von } \\
\text { Mises } \\
\text { Stress } \\
\text { S/NRatio }\end{array}$ & $\begin{array}{l}\text { Equiva- } \\
\text { lent von } \\
\text { Mises } \\
\text { Stress } \\
\text { (MPa) }\end{array}$ & $\begin{array}{l}\text { Equiva- } \\
\text { lent von } \\
\text { Mises } \\
\text { Stress } \\
\text { S/Nratio }\end{array}$ \\
\hline $\mathbf{1}$ & 1 & 1 & 1 & 566.78 & -54.492 & 761.81 & -57.136 \\
\hline $\mathbf{2}$ & 1 & 1 & 2 & 377.58 & -51.156 & 440.15 & -53.865 \\
\hline $\mathbf{3}$ & 1 & 2 & 1 & 460.97 & -54.258 & 668.25 & -57.329 \\
\hline $\mathbf{4}$ & 1 & 2 & 2 & 352.68 & -50.922 & 587.65 & -54.058 \\
\hline $\mathbf{5}$ & 2 & 1 & 1 & 613.44 & -55.872 & 674.75 & -55.929 \\
\hline $\mathbf{6}$ & 2 & 1 & 2 & 384.35 & -52.537 & 421.63 & -52.658 \\
\hline $\mathbf{7}$ & 2 & 2 & 1 & 642.98 & -55.638 & 616.6 & -56.122 \\
\hline $\mathbf{8}$ & 2 & 2 & 2 & 433.37 & -52.303 & 430.62 & -52.852 \\
\hline
\end{tabular}

Table 4

$\mathrm{S} / \mathrm{N}$ response table of parameter levels

\begin{tabular}{|l|c|c|c|c|c|c|}
\cline { 2 - 7 } \multicolumn{1}{c|}{} & \multicolumn{3}{c|}{ GROUP 1 } & \multicolumn{3}{c|}{ GROUP 2 } \\
\hline Level & A & B & C & A & B & C \\
\hline 1 & -52.71 & -53.51 & -55.07 & -55.60 & -54.90 & -56.63 \\
\hline 2 & -54.09 & -53.28 & -51.7 & -54.39 & -55.09 & -53.36 \\
\hline Delta & 1.38 & 0.23 & 3.34 & 1.21 & 0.19 & 3.27 \\
\hline $\begin{array}{l}\text { Sequ- } \\
\text { ence }\end{array}$ & $\mathbf{2}$ & $\mathbf{3}$ & $\mathbf{1}$ & $\mathbf{2}$ & $\mathbf{3}$ & $\mathbf{1}$ \\
\hline
\end{tabular}

When the $\mathrm{S} / \mathrm{N}$ responses of parameter levels in Table 4 were investigated, the most effective parameters on the minimum equivalent von Mises stress level in both groups of models, were determined to be the screw diameter $(\mathrm{C})$, the number of cortices (A), and the number of screws (B), respectively.

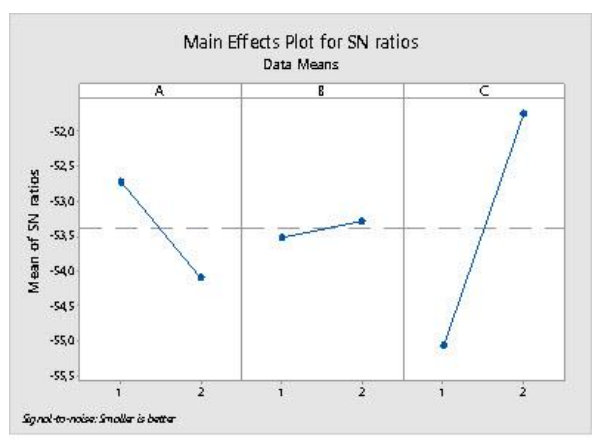

a

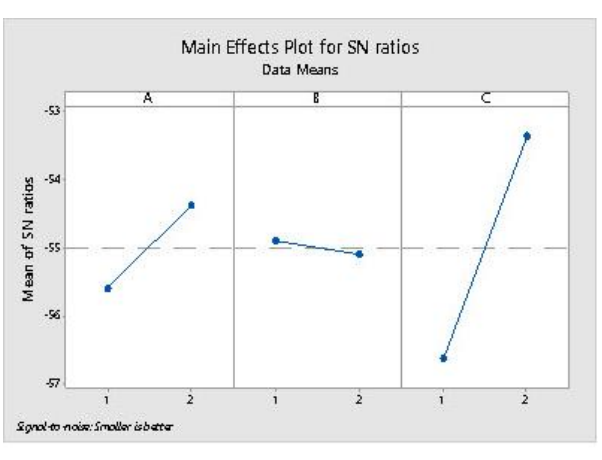

b

Fig. 3 Graphics showing $\mathrm{S} / \mathrm{N}$ ratios of model parameters for the equivalent von Mises stress results: a - GROUP 1; b - GROUP 2

The optimum levels of model parameters for both groups given in Table 2 are determined by the aid of Fig. 3. As illustrated, the level where the $\mathrm{S} / \mathrm{N}$ value is high is the optimum level among all parameter levels. The best value for any parameter was found by considering the largest $\mathrm{S} / \mathrm{N}$ ratio obtained among all levels of that parameter, thus optimum; in other words, the lowest equivalent von Mises stress levels obtained were as follows: for group 1 first level of cortex number (A1-3 cortices), second level of screw number (B2-2 screws) and second level of screw diameter (C2-diameter $4.5 \mathrm{~mm}$ ); for group 2 second level of cortex number (A2-4 cortices), first level of screw number (B1-1 screw) and second level of screw diameter (C2-diameter $4.5 \mathrm{~mm}$ ).

Interactions of all parameters used in the modelling 
design were determined by ANOVA analysis at a $95 \%$ reliability level. A p value $<0.05$ was accepted as significant. The results of this analysis are given in Table 5.

Table 5

Results of ANOVA analysis for Equivalent von Mises Stress level

\begin{tabular}{|l|l|l|l|l|l|l|}
\hline \multicolumn{7}{|c|}{ GROUP 1 } \\
\hline Parameter & DF & Seq SS & Adj SS & $\begin{array}{l}\text { Adj } \\
\text { MS }\end{array}$ & F & P \\
\hline A & 1 & 3.8110 & 3.8110 & 3.8110 & 5.78 & 0.074 \\
\hline B & 1 & 0.1096 & 0.1096 & 0.1096 & 0.17 & 0.704 \\
\hline C & $\mathbf{1}$ & $\mathbf{2 2 . 2 4 9 9}$ & $\mathbf{2 2 . 2 4 9 9}$ & $\mathbf{2 2 . 2 4 9 9}$ & $\mathbf{3 3 . 7 5}$ & $\mathbf{0 . 0 0 4}$ \\
\hline $\begin{array}{l}\text { Residual } \\
\text { Error }\end{array}$ & 4 & 2.6373 & 2.6373 & 0.6593 & & \\
\hline Total & 7 & 28.8077 & & & & \\
\hline Parameter & DF & Seq SS & Adj SS & $\begin{array}{l}\text { Adj } \\
\text { MS }\end{array}$ & F & P \\
\hline A & 1 & 2.9121 & 2.9121 & 2.9121 & 2.73 & 0.174 \\
\hline B & 1 & 0.0746 & 0.0746 & 0.0746 & 0.07 & 0.804 \\
\hline C & $\mathbf{1}$ & $\mathbf{2 1 . 3 9 8 0}$ & $\mathbf{2 1 . 3 9 8 0}$ & $\mathbf{2 1 . 3 9 8 0}$ & $\mathbf{2 0 . 0 7}$ & $\mathbf{0 . 0 1 1}$ \\
\hline $\begin{array}{l}\text { Residual } \\
\text { Error }\end{array}$ & 4 & 4.2654 & 4.2654 & 1.0663 & & \\
\hline Total & 7 & 28.6501 & & & & \\
\hline
\end{tabular}

In the ANOVA analysis, the parameter with the highest $\mathrm{F}$ level affects the results the most. Therefore, as shown in Table 5, screw diameter $(\mathrm{C})$ has the highest $\mathrm{F}$ value, and affects the equivalent von Mises stress the most in both of the groups. This effect of screw diameter was significant in both groups $(p<0.05)$. Other parameters did not affect the equivalent von Mises stress level significantly $(p>0.05)$.

\subsection{Modelling design for group 3}

Sixteen different modelling designs were produced by considering the insertion of screws as straight or oblique; each insertion type included eight models. The type of screw placement was also included as a parameter in this analysis. Parameters and their levels are shown in Table 6.

Modelling parameters and their levels

\begin{tabular}{|l|l|l|l|}
\hline Symbol & Parameters & Level 1 & Level 2 \\
\hline A & Number of Cortices & 3 & 4 \\
\hline B & Number of Screws & 1 & 2 \\
\hline C & Screw Diameter, mm & 3.5 & 4.5 \\
\hline D & $\begin{array}{l}\text { Type of Screw } \\
\text { Insertion }\end{array}$ & Oblique & Straight \\
\hline
\end{tabular}

When modelling parameters in Table 6 were considered, Taguchi L16 orthogonal array with 16 models was determined to be the most appropriate model. The L16 modelling design determined by the aid of the 'Minitab 17' software, the equivalent von Mises stress (MPa) results obtained from modelling studies, and signal-to-noise ratio $(\mathrm{S} / \mathrm{N})$ values are indicated in Table 7; the "smallest is best" analysis was used. The $\mathrm{S} / \mathrm{N}$ ratio analysis of each control parameter for the equivalent von Mises Stress is shown in Table 8.

Table 7

Modelling designs produced by using L16 orthogonal array, modelling results, and $\mathrm{S} / \mathrm{N}$ ratios

\begin{tabular}{|l|l|l|l|l|c|c|}
\hline $\begin{array}{c}\text { Mod } \\
\text { elNo }\end{array}$ & $\mathbf{A}$ & $\mathbf{B}$ & $\mathbf{C}$ & $\mathbf{D}$ & $\begin{array}{c}\text { Equivalent } \\
\text { von Mises } \\
\text { Stress, MPa }\end{array}$ & $\begin{array}{c}\text { Equivalent } \\
\text { von Mises } \\
\text { Stress } \\
\text { S/N ratio }\end{array}$ \\
\hline $\mathbf{1}$ & 1 & 1 & 1 & 1 & 761.81 & -56.612 \\
\hline $\mathbf{2}$ & 1 & 1 & 1 & 2 & 566.78 & -55.016 \\
\hline $\mathbf{3}$ & 1 & 1 & 2 & 1 & 440.15 & -53.309 \\
\hline $\mathbf{4}$ & 1 & 1 & 2 & 2 & 377.58 & -51.712 \\
\hline $\mathbf{5}$ & 1 & 2 & 1 & 1 & 668.25 & -56.592 \\
\hline $\mathbf{6}$ & 1 & 2 & 1 & 2 & 460.97 & -54.995 \\
\hline $\mathbf{7}$ & 1 & 2 & 2 & 1 & 587.65 & -53.289 \\
\hline $\mathbf{8}$ & 1 & 2 & 2 & 2 & 352.68 & -51.692 \\
\hline $\mathbf{9}$ & 2 & 1 & 1 & 1 & 674.75 & -56.699 \\
\hline $\mathbf{1 0}$ & 2 & 1 & 1 & 2 & 613.44 & -55.102 \\
\hline $\mathbf{1 1}$ & 2 & 1 & 2 & 1 & 421.63 & -53.396 \\
\hline $\mathbf{1 2}$ & 2 & 1 & 2 & 2 & 384.35 & -51.799 \\
\hline $\mathbf{1 3}$ & 2 & 2 & 1 & 1 & 616.6 & -56.679 \\
\hline $\mathbf{1 4}$ & 2 & 2 & 1 & 2 & 642.98 & -55.082 \\
\hline $\mathbf{1 5}$ & 2 & 2 & 2 & 1 & 430.62 & -53.375 \\
\hline $\mathbf{1 6}$ & 2 & 2 & 2 & 2 & 433.37 & -51.779 \\
\hline & & & & & \\
\hline
\end{tabular}

Table 8

S/N response table of parameter levels
\begin{tabular}{|l|c|c|c|c|}
\hline Level & A & B & C & D \\
\hline $\mathbf{1}$ & -54.15 & -54.21 & -55.85 & -54.99 \\
\hline $\mathbf{2}$ & -54.24 & -54.19 & -52.54 & -53.40 \\
\hline Delta & 0.09 & 0.02 & 3.30 & 1.60 \\
\hline Sequence & $\mathbf{3}$ & $\mathbf{4}$ & $\mathbf{1}$ & $\mathbf{2}$ \\
\hline
\end{tabular}

When the $\mathrm{S} / \mathrm{N}$ ratios of the parameter levels were investigated in Table 8, the most effective parameters on the minimum equivalent von Mises stress level were determined to be the screw diameter, type of screw insertion, number of cortices, and number of screws, respectively. 


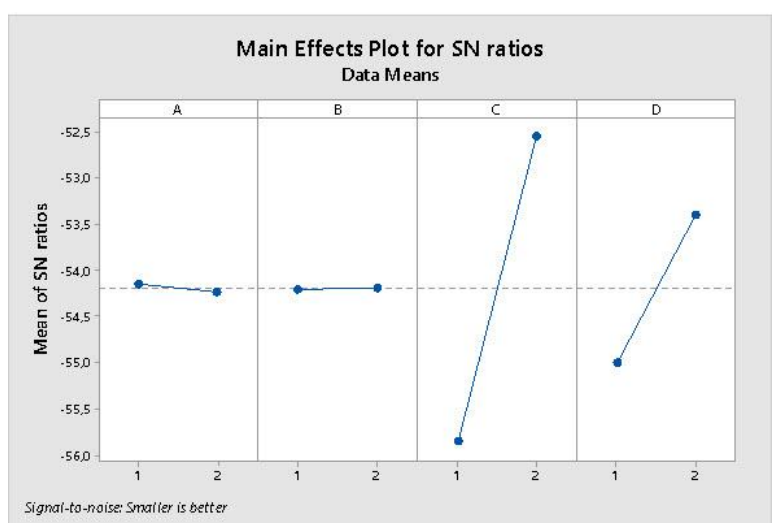

Fig. 4 Graphics showing the $\mathrm{S} / \mathrm{N}$ ratios of the model parameters for equivalent von Mises stress results

As illustrated in Fig. 4, the minimum equivalent von Mises stress levels obtained were as follows: first level of cortex number (A1-3 cortices), second level of screw number (B2- 2 screws), second level of screw diameter (C2- diameter $4.5 \mathrm{~mm}$ ), and second level of screw insertion type (D2- straight). The ANOVA analysis results performed in this model are presented in Table 9.

Results of ANOVA analysis for Equivalent von Mises Stress level

\begin{tabular}{|l|c|c|c|c|c|c|}
\hline Parameter & DF & Seq SS & Adj SS & $\begin{array}{c}\text { Adj } \\
\text { MS }\end{array}$ & F & P \\
\hline A & 1 & 0.0302 & 0.0302 & 0.0302 & 0.02 & 0.879 \\
\hline B & 1 & 0.0017 & 0.0017 & 0.0017 & 0.00 & 0.972 \\
\hline C & $\mathbf{1}$ & $\mathbf{4 3 . 6 4 3}$ & $\mathbf{4 3 . 6 4 3}$ & $\mathbf{4 3 . 6 4 3}$ & $\mathbf{3 4 . 8 3}$ & $\mathbf{0 . 0 0 0}$ \\
\hline D & $\mathbf{1}$ & $\mathbf{1 0 . 1 9 6}$ & $\mathbf{1 0 . 1 9 6}$ & $\mathbf{1 0 . 1 9 6}$ & $\mathbf{8 . 1 4}$ & $\mathbf{0 . 0 1 6}$ \\
\hline $\begin{array}{l}\text { Residual } \\
\text { Error }\end{array}$ & 11 & 13.782 & 13.782 & 1.252 & & \\
\hline Total & 15 & 67.654 & & & & \\
\hline
\end{tabular}

As shown in Table 9, the $\mathrm{F}$ value of the screw diameter was the highest $(F=34.83)$, and thus it had the greatest effect on the equivalent von Mises stress level. The effects of screw diameter and type of screw insertion on the equivalent von Mises stress level were significant $(p=0.000$ and $p=0.016$, respectively). Other parameters did not show significant effects on the equivalent von Mises stress level $(p>0.05)$.

The results of three different modelling designs performed by the Taguchi method are summarized and compared in Table 10.

As shown in Table 10, the most important parameters of modelling design with the Taguchi method in group 3 were similar to those of group 1 and group 2, with the exception that in group 3 , the type of screw insertion was second in importance, which was an additional parameter of this group.

When the optimum model levels were considered, the fourth model was the most optimal in group 1 (straight screw insertion) and group 3 (both straight and oblique screw insertions). The equivalent von Mises stress (MPa) values of these models were $352.68 \mathrm{MPa}$. The optimum equivalent von Mises stress values obtained by the Taguchi method analysis in these three groups were the same with the minimum values obtained by ANSYS Workbench (version 15.0) software, and this result indicates that modelling design is proper.

As shown in Table 10, screw diameter was statistically significant through ANOVA analysis in all three groups. Thus, in the current study this parameter was the most important one in the modelling design.

Table 10

Summary of modelling design produced by Taguchi method

\begin{tabular}{|c|c|c|c|}
\hline & GROUP 1 & GROUP 2 & GROUP 3 \\
\hline $\begin{array}{l}\text { Respec- } \\
\text { tive im- } \\
\text { portance } \\
\text { of modal } \\
\text { Parame- } \\
\text { ters }\end{array}$ & $\begin{array}{l}\text { Screw diameter } \\
\text { Number of } \\
\text { cortices } \\
\text { Number of } \\
\text { screws }\end{array}$ & $\begin{array}{l}\text { Screw di- } \\
\text { ameter } \\
\text { Number of } \\
\text { cortices } \\
\text { Number of } \\
\text { screws }\end{array}$ & $\begin{array}{c}\text { Screw diameter } \\
\text { Type of screw in- } \\
\text { sertion } \\
\text { Number of cortices } \\
\text { Number of screws }\end{array}$ \\
\hline $\begin{array}{l}\text { Opti- } \\
\text { mum } \\
\text { model } \\
\text { level }\end{array}$ & $\begin{array}{l}\mathrm{A} 1 \mathrm{~B} 2 \mathrm{C} 2= \\
=4 . \mathrm{model}\end{array}$ & $\begin{array}{l}\mathrm{A} 2 \mathrm{~B} 1 \mathrm{C} 2= \\
=6 . \mathrm{model}\end{array}$ & $\begin{array}{c}\mathrm{A} 1 \mathrm{~B} 2 \mathrm{C} 2 \mathrm{D} 2= \\
=4 . \text { model }\end{array}$ \\
\hline $\begin{array}{c}\text { Opti- } \\
\text { mum } \\
\text { equiva- } \\
\text { lent von } \\
\text { Mises } \\
\text { stress, } \\
\text { MPa }\end{array}$ & 352.68 & 421.63 & 352.68 \\
\hline $\begin{array}{l}\text { Parame- } \\
\text { ters with } \\
p<0.05\end{array}$ & Screw diameter & $\begin{array}{l}\text { Screw di- } \\
\text { ameter }\end{array}$ & $\begin{array}{l}\text { Screw diameter } \\
\text { Type of screw in- } \\
\text { sertion }\end{array}$ \\
\hline
\end{tabular}

\section{Discussion}

The syndesmotic complex is the most complicated ligament of the ankle [22]. Since load distribution between the tibia, fibula, and talus changes continuously during the motion of walking, mechanisms of injury also vary considerably. Ankle injuries are especially observed more frequently in youth and athletes, and this fact increases their importance and seriousness $[23,24]$. The syndesmotic ligament and distal tibiofibular joint must be kept in ideal anatomy (it may be achieved by keeping the tibiofibular intra-articular distance 2-3 mm) [25]. For successful treatment, ideal reduction achieved during surgical treatment must be maintained during the postoperative period. An increase or decrease in the distance between the tibia and fibula may lead to progressive instability in the ankle, osteoarthritis, and pain [26]. Syndesmosis injuries may be roughly defined in three groups, as mild, moderate, and serious. Serious syndesmotic injuries require surgical treatment [27].

The most clinical and biomechanical studies about syndesmosis injuries include the method of screw fixation. The main topics studied in this respect are the properties of the screw, its number, and attachment to the cortex. In our study, models in 16 different configurations were generated with regard to screw diameter, screw number, number of 
cortices, and method of screw placement. Since the fibula is thin, and due to its association with other injuries, it is not always possible to use a screw with a diameter of $4.5 \mathrm{~mm}$; screws with diameters of $3.5 \mathrm{~mm}$ were alternatively used. Since the use of fully-threaded cortical screws is recommended by the Association for the Study of Internal Fixation Manual of Internal Fixation, fully-threaded cortical screws were used instead of malleolar screws in one study [28].

The most important parameter among the modelling design parameters was screw diameter. When screws with diameters of $4.5 \mathrm{~mm}$ and $3.5 \mathrm{~mm}$ were compared, the lowest equivalent von Mises stress value in all configurations was determined with screws with $4.5 \mathrm{~mm}$ diameter; this value obtained with screws with a diameter of $4.5 \mathrm{~mm}$ in all models was nearly half of the values obtained with screws having diameters of $3.5 \mathrm{~mm}$. This result indicates that use of $4.5 \mathrm{~mm}$ diameter screws of would offer a more potent and durable section when compared to that with $3.5 \mathrm{~mm}$ diameter. This finding is parallel to that found in the study of Hansen et al. [29].

Xenos et al. (1995) reported that two screws instead of one would provide more stability in the treatment of syndesmosis injuries [30]. However, Penera et al. (2014) reported in a cadaver study that when two syndesmosis screws are inserted, there could be a high risk of the proximal screw to injure the perforators of the peroneal artery [31]. Stuart and Panchbhavi (2011) determined that suprasyndesmotic and transsyndesmotic screw insertions led to similar clinical and radiological results [32].

The current study determined that the equivalent von Mises stress decreased in fixations with two screws inserted through three cortices, whereas this parameter did not decrease in fixations through four cortices. This result may possibly be attributed to the negative effect of four cortices, rather than the two screws. Thus, if the region is appropriate, fixation with two screws may be preferred.

Karapınar et al. (2007) indicated that syndesmosis fixation through four cortices results in a greater risk of tibiofibular synostosis and motion restriction, when compared to three-cortex fixation [33]. Wikeroy et al. (2010) determined in their clinical study that three- or four-cortex syndesmotic fixation did not differ in regard to clinical and radiological findings [34].

In contrast to our expectations, in the first group of models in which straight screw insertion was performed; three-cortex fixation resulted in a lower equivalent von Mises stress level when compared with the four-cortex fixation. The higher loading exerted on the screw determined in fourcortex fixation indicates that the screw is motionless at four points, and it is under great stress; tibiofibular joint stiffness, synostosis, and screw fixation failure may be the result of this extreme loading.

In the first group of models in this study, threecortex fixation with two screws led to a lower equivalent von Mises stress value when compared to one screw, whereas four-cortex fixation with two screws resulted in a higher equivalent von Mises stress values when compared to one screw. This finding was also attributed to the negative influence of four cortices, rather than the number of screws. The most ideal model in the first group was the three-cortex fixation with two screws in diameters of $4.5 \mathrm{~mm}$, which caused the lowest equivalent von Mises stress values.

Another important matter of debate is the requirement for early removal of the screw in the cases of three- or four-cortex fixation. Bell and Wong (2006) and Hoiness and Stromsoe (2004) consider that screw removal is not obligatory in the three-cortex fixation [35, 36]. However, Melvin et al. (2008) recommend removal of the screw before the patient stands up in the cases of four-cortex syndesmosis repair [37]. If not removed, it may cause osteoarthritis, screw breakage, and persistent pain. In the biomechanical study of Liu et al. (2013), removal of the syndesmosis screw is recommended so that the tibiofibular joint can achieve the physiological transfer of loading [38]. When not removed, they claim that the joint may not be able to mimic physiological motions and loading transfer, which will cause development of joint stiffness, pain, and arthrosis.

In the first group, the lowest equivalent von Mises stress develops in the case of three-cortex fixation with two screws in diameters of $4.5 \mathrm{~mm}$; in this case the patient may be mobilized earlier without removal of the screw, and there may be no need for a second operation.

In the present study, screw diameter was the most important variable when the screw was inserted at a 30 degree angle to the joint; an increase in the screw diameter was shown to decrease the equivalent von Mises stress value. However, in contrast to the results found in the first group, four-cortex fixation decreased the equivalent von Mises stress value when compared to the three-cortex fixation. Fixation with two screws with diameters of $3.5 \mathrm{~mm}$ caused a lower equivalent von Mises stress value when compared to fixation with one screw. However, fixation with two screws with diameters of $4.5 \mathrm{~mm}$ led to a higher equivalent von Mises stress value when compared to fixation with one screw. The reason for this contradiction is due to the fact that the thicker screw penetrates more through the tibia, and the second screw therefore provides more rigid fixation, and thus increases the stress exerted on the screw. Oblique insertion of the screw may be needed during some surgical conditions. In the second group, the lowest equivalent von Mises stress value was determined in the case of four-cortex fixation with one screw with a diameter of $4.5 \mathrm{~mm}$.

Limitations of the study can be listed as follows: CT images of one subject are not adequate for the production of models. The present simulation makes it nearly impossible to mimic a complicated structure such as the ankle, which includes complex ligaments and produces complex motions. It was not supported by clinical studies, which is another handicap. Especially the oblique insertion of the screw in syndesmosis fixation is not a routine clinical trial, and clinical applications are also required.

\section{Conclusion}

When the optimum model levels are considered, the fourth model was the optimal in both group 1 (straight insertion of the screw) and group 3 (straight and oblique insertions of the screws). The equivalent von Mises stress (MPa) values in these models were $352.68 \mathrm{MPa}$. The analyses results of the three groups obtained by the Taguchi method with regard to the optimum equivalent von Mises Stress values were the same as the minimum values obtained by the ANSYS Workbench (version 15.0) software, which indicates that the modelling design was properly generated.

This study is the first biomechanical study that included all the parameters that are used in the studies of ankle biomechanics, such as the screw diameter, screw number, number of cortices, and the angle of screw insertion. 


\section{References}

1. Ogilvie-Harris, D.J.; Reed, S.C.; Hedman, T.P. 1994. Disruption of the ankle syndesmosis: biomechanical study of the ligamentous restraints, Arthroscopy 10(5): 558-560.

http://dx.doi.org/10.1016/S0749-8063(05)80014-3.

2. Michelson, J.; Solocoff, D.; Waldman, B.; Kendell, K.; Ahn, U. 1997. Ankle fractures: The Lauge-Hansen classification revisited, Clin Orthop 345: 198-205.

3. Hamid, N.; Loeffler, B.J.; Braddy, W.; Kellam, J.F.; Cohen, B.E.; Bosse, M.J. 2009. Outcome after fixation of ankle fractures with aninjury to the syndesmosis: the effect of the syndesmosis screw, J Bone Joint Surg Br. 91(8): 1069-1073.

http://dx.doi.org/10.1302/0301-620X.91B8.22430.

4. Porter, D.A.; Jaggers, R.R.; Barnes, A.F.; Rund, A.M. 2014. Optimal management of ankle syndesmosis injuries, Open Access Journal of Sports Medicine 5: 173-182.

http://dx.doi.org/10.2147/OAJSM.S41564.

5. Er, M.S.; Verim, O.; Eroglu, M.; Altinel, L.;Gokce, B.; Tasgetiren, S. 2015. Biomechanical evaluation of syndesmotic screw design via finite element analysis and taguchi's method, J Am Podiatr Med Assoc. 105(1): 1421.

http://dx.doi.org/10.7547/8750-7315-105.1.14.

6. Walker, L.; Willis, N. 2015. Weber C ankle fractures: a retrospective audit of screw number, size, complications, and retrieval rates, J Foot Ankle Surg. 54: 454-457. http://dx.doi.org/10.1053/j.jfas.2014.11.015.

7. Peek, A.C.; Fitzgerald, C.E.; Charalambides, C. 2014. Syndesmosis screws: how many, what diameter, where and should they be removed? A literature review, Injury. 45(8): 1262-7. http://dx.doi.org/10.1016/j.injury.2014.05.003.

8. Schepers, T. 2011. To retain or remove the syndesmotic screw: a review of literature, Arch Orthop Trauma Surg. 131(7): 879-83.

http://dx.doi.org/10.1007/s00402-010-1225-x.

9. Jordan, T.H.; Talarico, R.H.; Schuberth, J.M. 2011. The radiographic fate of the syndesmosis after trans syndesmotic screw removal in displaced ankle fractures, J Foot Ankle Surg. 50(4): 407-12. http://dx.doi.org/10.1053/j.jfas.2011.03.014.

10. Özkan, A.; Atmaca, H.; Mutlu, İ.; Çelik, T.; Uğur, L.; Kişioğlu, Y. 2013. Stress distribution comparisons of foot bones in patient with tibia vara: a finite element study, Acta of Bioengineering and Biomechanics 15(4). http://dx.doi.org/10.5277/abb130409.

11. Walke, W.; Paszenda, Z.; Kaczmarek, M. 2008. Biomechanical analysis of tibia double threaded screw fixation, Arch Mater Sci Eng. 30: 41-44.

12. Gray, H.A.; Taddei, F.; Zavatsky, A.B.; Cristofolini, L.; Gill, H.S. 2008. Experimental validation of a finite element model of a human cadaveric tibia, J Biomech Eng. 130(3): 031016. http://dx.doi.org/10.1115/1.2913335.

13. Haraguchi, N.; Armiger, R.S.; Myerson, M.S.; Campbell, J.T.; Chao, E.Y. 2009. Prediction of threedimensional contact stress and ligament tension in the ankle during stance determined from computational modeling, Foot Ankle Int. 30: 177-185. http://dx.doi.org/10.3113/FAI.2009.0177.
14. Beumer, A.; Van Hemert, W.L.; Swierstra, B.A.; Jasper, L.E.; Belkoff, S.M.2003. A biomechanical evaluation of the tibiofibular and tibiotalar ligaments of the ankle, Foot Ankle Int. 24: 426-429.

http://dx.doi.org/10.1177/107110070302400509.

15. Attarian, D.E.; McCrackin, H.J.; DeVito, D.P.; McElhaney, J.H.; Garrett, W.E 1985. Biomechanical characteristics of human ankle ligaments, Foot Ankle. 6: 54-58.

16. Stauffer, R.N.; Chao, E.Y.; Brewster, R.C. 1977. Force and motion analysis of the normal, diseased, and prosthetic ankle joint. Clin Orthop Relat Res., 189-196.

17. Ross, P.J. 1996. Taguchi Techniques for Quality Engineering: Loss Function, Orthogonal Experiments, Parameter and Tolerance Design - 2nd ed. New York. NY: McGraw-Hill, 329 p.

18. Wang W.H.; Tarng Y.S. 1998. Design optimisation of cutting parameters for turning operations based on the taguchi method, Journal of Materials Processing Technology 84: 122-129.

http://dx.doi.org/10.1016/S0924-0136(98)00079-X.

19. Asiltürk, İ.; Akkuş, H. 2011. Determining the effect of cutting parameters on surface roughness in hard turning using the Taguchi method, Measurement 44(9): 16971704 . http://dx.doi.org/10.1016/j.measurement.2011.07.003.

20. Palanikumar, K. 2011. Experimental investigation and optimisation in drilling of GFRP composites, Measurement 44(10): 2138-2148. http://dx.doi.org/10.1016/j.measurement.2011.07.023.

21. Chen, Y.H; Tam, S.C.; Chen, W.L.; Zhengy, H.Y. 1996. Application of taguchi method in the optimization of laser micro-engraving of photomasks, International Journal of Materials \& Product Technology. 11:333344. http://dx.doi.org/10.1504/IJMPT.1996.036336.

22. Browner, B.D. 2009. Skeletal Trauma: Basic Science, Management, and Reconstruction, Philadelphia (PA): Saunders/Elsevier, 2704 p.

23. Press, C.M.; Gupta, A.; Hutchinson, M.R. 2009. Management of ankle syndesmosis injuries in the athlete, Current Sports Medicine Reports 8: 228-233. http://dx.doi.org/10.1249/JSR.0b013e3181b7ec0c.

24. Williams, G.N.; Jones, M.H.; Amendola, A.2007. Syndesmotic ankle sprains in athletes, American Journal of Sports Medicine 35: 1197-1207. http://dx.doi.org/10.1177/0363546507302545.

25. Harper, M.C.; Keller, T.S. 1989. A radiographic evaluation of the tibiofibular syndesmosis, Foot Ankle. 10: 156-160. http://dx.doi.org/10.1177/107110078901000308.

26. Sagi, H.C.; Shah, A.R.; Sanders, R.W. 2012. The functional consequence of syndesmotic joint malreduction at a minimum 2-year follow-up, J Orthop Trauma 26: 439-43. http://dx.doi.org/10.1097/BOT.0b013e31822a526a.

27. Bauer, A.S.; Blumanb, E.M.; Wilsona, M.G.; Chiodoa, C.P. 2009. Injuries of the distal lower extremity syndesmosis, Current Orthopaedic Practice 20: 111-116. http://dx.doi.org/10.1097/BCO.0b013e31819b04eb.

28. Müller, M.E.; Allgower, M.; Schneider, R.; Willenegger, H. 1992. Manual of Internal Fixation, New York, NY: Springer-Verlag, 409 p.

29. Hansen, M.; Le, L.; Wertheimer, S.; Meyer, E.; 
Haut, R. 2006. Syndesmosis fixation: analysis of shear stress via axial load on 3.5-mmand 4.5-mm quadricortical syndesmotic screws, J Foot Ankle Surg. 45(2): 6569. http://dx.doi.org/10.1053/j.jfas.2005.12.004.

30. Xenos, J.S.; Hopkinson, W.J.; Mulligan, M.E.; Olson, E.J.; Popovic, N.A. 1995. The tibiofibular syndesmosis. Evaluation of the ligamentous structures, methods of fixation, and radiographic assessment, $\mathrm{J}$ Bone Joint Surg Am. 77(6): 847-856. http://dx.doi.org/10.2106/00004623-199506000-00005.

31. Penera, K.; Manji, K.; Wedel, M.; Shofler, D.; Labovitz J. 2014. Ankle syndesmotic fixation using two screws: risk of injury to the perforating branch of the peroneal artery, J Foot Ankle Surg. 53(5): 534-8. http://dx.doi.org/10.1053/j.jfas.2014.04.006.

32. Stuart, K.; Panchbhavi, V.K. 2011. The fate of syndesmotic screws, Foot Ankle Int. 32: 519-525. http://dx.doi.org/10.3113/FAI.2011.0519.

33. Karapinar, H.; Kalenderer, O.; Karapinar, L.; Altay, T.; Manisali, M.; Gunal, I. 2007. Effects of three- or four-cortex syndesmotic fixation in ankle fractures, J Am Podiatr Med Assoc. 97(6): 457-459. http://dx.doi.org/10.7547/0970457.

34. Wikeroy, A.K.; Hoiness, P.R.; Andreassen, G.S.; Hellund, J.C.; Madsen, J.E. 2010 No difference in functional and radiographic results 8.4 years after quadricortical compared with tricortical syndesmosis fixation in ankle fractures, J Orthop Trauma. 24(1): 17-23. http://dx.doi.org/10.1097/BOT.0b013e3181bedca1.

35. Bell, D.P.; Wong, M.K. 2006. Syndesmotic screw fixation in Weber $C$ ankle injuries: should the screw be removed before weight bearing Injury, 37(9): 891-898. http://dx.doi.org/10.1016/j.injury.2006.02.003.

36. Hoiness, P.; Stromsoe, K. 2004.Tricortical versus quadricortical syndesmosis fixation in ankle fractures: a prospective, randomized study comparing two methods of syndesmosis fixation, J Orthop Trauma. 18(6): 331-337. http://dx.doi.org/10.1097/00005131-200407000-00001.

37. Melvin, J.S.; Downing, K.L.; Ogilvie, C.M. 2008. A technique for removal of broken cannulated tricortical syndesmotic screws. J Orthop Trauma. 22(9): 648-651. http://dx.doi.org/10.1097/BOT.0b013e3181886f74.

38. Liu, Q.; Zhang, K.; Zhuang, Y.; Li, Z.; Yu B.; Pei, G. 2013. Analysis of the stress and displacement distribution of inferior tibiofibular syndesmosis injuries repaired with screw fixation: a finite element study, PLoS One, 8(12): e80236.

http://dx.doi.org/10.1371/journal.pone.0080236.
H. Göçer, A. Çirakli, L. Uğur, A. Yildiz, S.Karadeniz

\section{DETERMINATION OF THE MOST APPROPRIATE SURGICAL TREATMENT IN SYNDESMOTIC INJURY OF ANKLE JOINT: APPLICATION OF TAGUCHI METHOD}

S u m m a r y

Background: Ankle injuries are more frequently observed in youth and athletes, and may lead to permanent disabilities if not treated properly. Approximately $10 \%$ of ankle injuries are associated with syndesmotic ligament injuries and fixation with screw is frequently applied as surgical treatment. The present study we aimed to determine the most proper model and model parameters by evaluating the minimum equivalent von Mises stress value developed in syndesmotic fixation of the ankle.

Methods: By modeling the normal lower extremity in a healthy subject via the finite element analysis (FEA) method, we compared stress developed in a normal standing position in the models of syndesmotic injuries approached by frequently used cortical screws of various lengths and diameters, and by considering the number of screws and localization of fixation. Tibia, fibula, talus, and calcaneus were modeled as a three dimensional (3D) solid model via images of computerized tomography (CT), using the MIMICS program (version 10.01). The obtained 3D model was saved in the MIMICS program in STL (steriolithography) format, and transferred to the Geomagic Studio (version 10) program. Essential corrections were applied to the bones with the aid of the Geomagic program. The model of lower extremity designed was transferred to the Solidworks (version 2014) program in IGES (Initial Graphics Exchange Specification) format, and thus the meniscus and cartilage were modeled. Tensions that developed in the ankle were calculated after forming a mesh pattern via the ANSYS Workbench (version 15.0) software.

Results: Sixteen different models obtained were analyzed by the Taguchi method, and the most appropriate models and model parameters were indicated by determining the minimum equivalent von Mises stress value.

Conclusion: Screw diameter was determined to be the most important parameter. When 16 different models were considered, a screw diameter of $4.5 \mathrm{~mm}$ and threecortex fixation with two screws parallel to the tibial joint surface were found to produce the most convenient model.

Keywords: ankle, biomechanical, finite element model, syndesmosis, screw fixation, Taguchi method.

Received January 22, 2016 Accepted February 06, 2017 